\title{
ASO Author Reflections: Robotic Oncologic Surgery
}

\author{
June S. Peng, MD, Steven N. Hochwald, MD, MBA, and Moshim Kukar, MD \\ Department of Surgical Oncology, Roswell Park Comprehensive Cancer Center, Buffalo, NY
}

\section{PAST}

Minimally invasive approaches for oncologic surgery have been steadily gaining favor, with lower complication rates in randomized trials for both laparoscopic and thoracoscopic ${ }^{1}$ and robotic ${ }^{2}$ esophagectomies compared with open esophagectomy. Analysis of the National Cancer Database shows increasing adoption of minimally invasive techniques over time, with $55.9 \%$ of esophagectomies performed using a minimally invasive approach in $2015 .^{3}$ However, these approaches can be challenging to perform, with significant learning curves to achieve these results.

\section{PRESENT}

Our group has performed laparoscopic and thoracoscopic esophagectomies for many years. A recent analysis of outcomes of this technique from our group showed an $8.1 \%$ conversion rate, $5.1 \%$ leak rate (all managed nonoperatively), and $5.1 \%$ stricture rate. ${ }^{4}$ Our rationale for shifting from the laparoscopic to robotic approach included better visualization, more stable platform, ease of intracorporeal suturing, as well as practical issues of ergonomics and decreased reliance on a skilled assistant.

\footnotetext{
This ASO Author Reflections is a brief invited commentary on the article "Technique for Robotic Ivor Lewis Esophagectomy with 6-cm Linear Stapled Side-to-Side Anastomosis”. Ann Surg Oncol. 2020. https://doi.org/10.1245/s10434-019-07933-4.
}

(C) Society of Surgical Oncology 2020

First Received: 14 October 2019;

Published Online: 28 July 2020

M. Kukar, MD

e-mail: moshim.kukar@ roswellpark.org

\section{FUTURE}

Our video article $^{5}$ presents our current technique for robotic Ivor Lewis esophagectomy. It reflects several iterations of changes in port placement and technique and represents what we find to be the optimized approach currently. We hope that the results of our learning curve in this complex operation will present ideas for experienced surgeons and offer details for those looking to start a robotic esophagectomy program.

DISCLOSURES The authors declare no conflicts of interest.

\section{REFERENCES}

1. Biere SS, van Berge Henegouwen MI, Maas KW, et al. Minimally invasive versus open oesophagectomy for patients with oesophageal cancer: a multicentre, open-label, randomised controlled trial. Lancet. 2012; 379(9829):1887-92.

2. van der Sluis PC, van der Horst S, May AM, et al. Robot-assisted minimally invasive thoracolaparoscopic esophagectomy versus open transthoracic esophagectomy for resectable esophageal cancer: a randomized controlled trial. Ann Surg. 2019; 269(4):621-30.

3. Espinoza-Mercado F, Imai TA, Borgella JD, et al. Does the approach matter? Comparing survival in robotic, minimally invasive and open esophagectomies. Ann Thorac Surg. 2019;107(2):378-85.

4. Kukar M, Ben-David K, Peng JS, et al. Minimally invasive Ivor Lewis esophagectomy with linear stapled anastomosis associated with low leak and stricture rates. J Gastrointest Surg. 2019. https://doi.org/10.1007/s11605-019-04320-y.

5. Peng JS, Nurkin SJ, Hochwald SN, et al. Technique for robotic Ivor Lewis esophagectomy with 6-cm linear stapled side-to-side anastomosis. Ann Surg Oncol. 2020;27(3):824. https://doi.org/10. 1245/s10434-019-07933-4.

Publisher's Note Springer Nature remains neutral with regard to jurisdictional claims in published maps and institutional affiliations. 